\title{
Intrapleural Streptokinase for the Treatment of Chylothorax
}

\author{
Yeh Chunn Kuan MRCP, Soon Hin How MMED, Teck Han Ng MRCP, \\ and Mohammed Fauzi Abdul Rani FRCP
}

\begin{abstract}
Chylothorax is suspected when milky white turbid fluid is obtained from thoracocentesis. Conservative management usually involves intercostal tube drainage, dietary restriction, and total parenteral nutrition. Surgery is indicated when conservative management fails. We describe a young woman with idiopathic chylothorax who failed conservative therapy but refused surgery. We instilled intrapleural streptokinase, which improved her condition. Key words: chylothorax; streptokinase; pleural effusion; chylothorax. [Respir Care 2011;56(12):1953-1955. (C 2011 Daedalus Enterprises]
\end{abstract}

\section{Introduction}

Chylothorax is suspected when milky white turbid fluid is obtained from thoracocentesis. Conservative management usually involves intercostal tube drainage, dietary restriction, and total parenteral nutrition. Surgery is indicated when conservative management fails. We describe a young woman with idiopathic chylothorax who failed conservative therapy but refused surgery. We instilled intrapleural streptokinase, which improved her condition.

\section{Case Report}

A 22-year-old woman with no previous medical illnesses presented with worsening breathlessness, reduced appetite, and $1 \mathrm{~kg}$ of weight loss in the month before admission. She had no fever, chest pain, cough, joint pain, night sweats, history of trauma, or contact with any patient with tuberculosis, and she denied high-risk behaviors.

On clinical examination she was alert, well nourished, and afebrile. Her blood pressure was 102/73 mm Hg, heart rate 94 beats/min, respiratory rate 30 breaths/min, and oxygen saturation $90 \%$ on room air. There was stony dull-

\footnotetext{
The authors are affiliated with the Department of Internal Medicine, International Islamic University of Malaysia, Kuantan, Malaysia.

The authors have disclosed no conflicts of interest.

Correspondence: Kuan Yeh Chunn MRCP, Department of Internal Medicine, International Islamic University of Malaysia, PO Box 141, 25710 Kuantan, Malaysia. E-mail: kychunn@yahoo.com.
}

DOI: $10.4187 /$ respcare. 01207 ness and absent breath sounds throughout her left hemithorax. There was no palpable enlargement of the liver or spleen, nor lymphadenopathy. All other systems were unremarkable.

Chest radiograph showed massive left-side pleural effusion and the trachea and mediastinum shifted to the right (Fig. 1). We inserted an intercostal tube, which drained 2,230 mL of turbid milky white fluid overnight. Her breathlessness improved. Analysis of the fluid reported triglyceride content of $5.80 \mathrm{mmol} / \mathrm{L}(516 \mathrm{mg} / \mathrm{dL})$ and cholesterol of $0.31 \mathrm{mmol} / \mathrm{L}(12.1 \mathrm{mg} / \mathrm{dL})$, which confirmed the diagnosis of chylothorax. Pleural fluid culture, anti-nuclear antibody, and rheumatoid factor were all negative. Thyroid function test was normal. Other than the left-side pleural effusion, the computed tomogram showed no lung lesions, intrathoracic lymphadenopathy, or evidence of trauma to the thoracic duct.

After discussing the treatment options with the patient, we decided to treat her conservatively for 2 weeks before considering surgery. She started on a fat-free diet, medium-chain triglycerides oil, and total parenteral nutrition via central venous catheter. On hospital day 14 she developed a high fever $\left(39^{\circ} \mathrm{C}\right)$. She did not complain of cough or worsening breathlessness. Her blood pressure was 102/ $68 \mathrm{~mm} \mathrm{Hg}$, her heart rate was 80 beats/min, and intercostal drainage obtained $800 \mathrm{~mL}$ of chyle per day. She was started empirically on intravenous cefoperazone plus sulbactam ( $1 \mathrm{~g}$ twice daily) for suspected nosocomial pneumonia. However, blood, urine, and repeat pleural fluid cultures returned negative.

On hospital day 20 her intercostal tube stopped draining, despite repeated flushing with normal saline, and was removed. Another computed tomogram 2 days later (Fig. 2) 


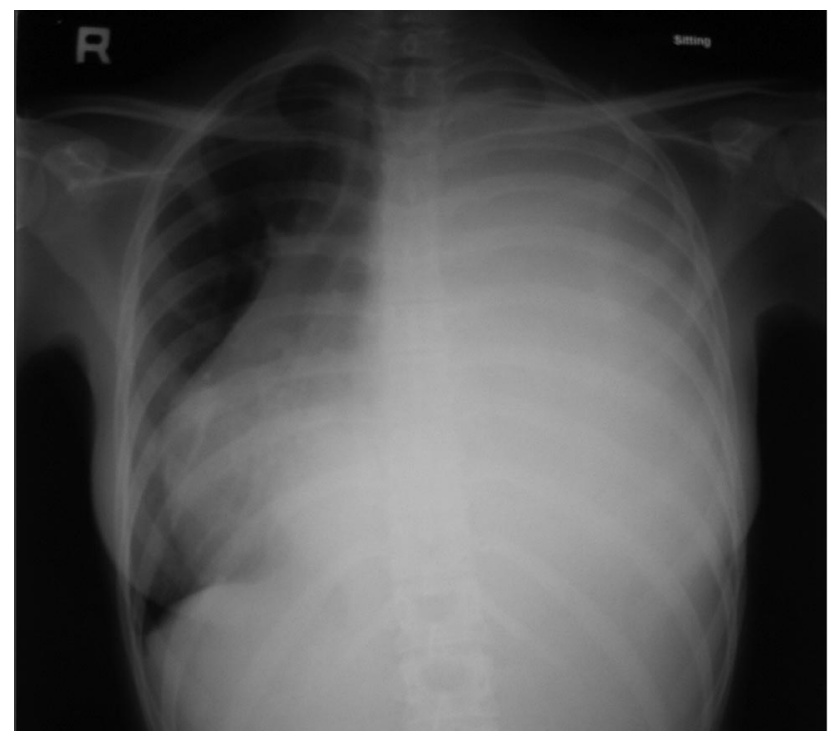

Fig. 1. Chest radiograph shows massive left-side pleural effusion and trachea and mediastinum shifted to the right.

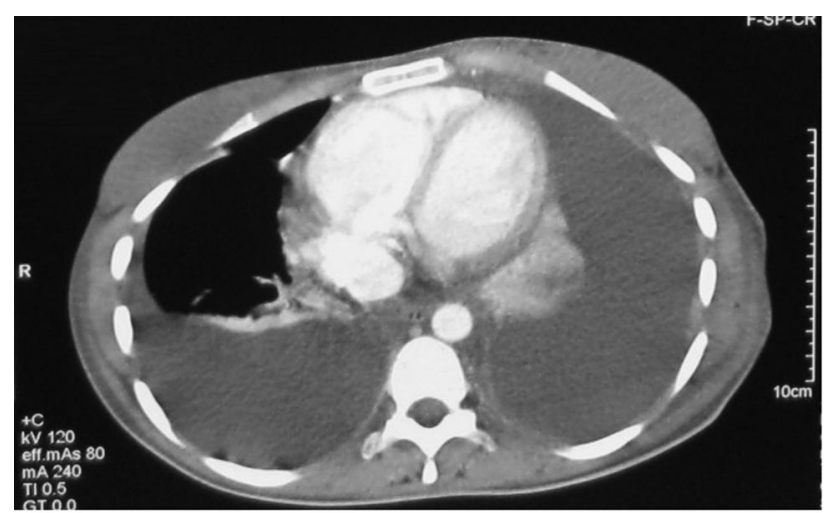

Fig. 2. Computed tomogram shows persistent left chylothorax and right-side lower-lobe consolidation and pleural effusion.

revealed a persistent left pleural effusion and emergence of a right pleural effusion and right lower lobe consolidation. Left thoracocentesis obtained chylous material, and an intercostal tube was re-inserted on the left side. Pleural fluid analysis results were: lactate dehydrogenase $417 \mathrm{U} / \mathrm{L}$ (serum $278 \mathrm{U} / \mathrm{L}$ ), total protein $20.3 \mathrm{~g} / \mathrm{L}$ (serum $62.6 \mathrm{~g} / \mathrm{L}$ ), glucose $4.8 \mathrm{mmol} / \mathrm{L}$ (serum $4.9 \mathrm{mmol} / \mathrm{L}$ ), triglyceride $2.14 \mathrm{mmol} / \mathrm{L}$, and total cholesterol $0.89 \mathrm{mmol} / \mathrm{L}$. Thoracocentesis was also performed on the right hemithorax, which drained 1,200 $\mathrm{mL}$ of straw-colored fluid with lactate dehydrogenase $94 \mathrm{U} / \mathrm{L}$ (serum $278 \mathrm{U} / \mathrm{L}$ ), protein $18.8 \mathrm{~g} / \mathrm{L}$ (serum $62.6 \mathrm{~g} / \mathrm{L}$ ), glucose $5.6 \mathrm{mmol} / \mathrm{L}$ (serum $4.9 \mathrm{mmol} / \mathrm{L}$ ), triglyceride $1.86 \mathrm{mmol} / \mathrm{L}$, and cholesterol $0.80 \mathrm{mmol} / \mathrm{L}$. Pleural fluid cultures from the right and left thoracocenteses were negative. The provisional diagnoses were bilateral chylothoraces and right-side nosocomial pneumonia. No further intervention was planned for the right chylothorax because it did not recur following thoracocentesis.

She continued to receive intravenous cefoperazone plus sulbactam ( $1 \mathrm{~g}$ twice daily) for 2 weeks. The left intercostal tube continued to drain poorly, despite persistent left chylothorax seen on chest radiograph. We suspected that pleural adhesions had formed and caused multiloculated effusions and poor intercostal tube drainage. Attempts to facilitate drainage with intercostal tube flushing with normal saline were unsuccessful. We advised surgery, but she refused. We administered intrapleural streptokinase: 250,000 units twice daily for 3 days. The daily pleural drainage was nil before, but following instillation of intrapleural streptokinase, an additional $2,700 \mathrm{~mL}$ was drained over those 3 days.

A subsequent chest radiograph showed an expanded left lung and a normal right lung. The intercostal tube was removed and she was discharged on day 43 . She continued a low-fat diet for 4 weeks. On review one month later, she was well. She had no fever, cough, or dyspnea, and her appetite and general well-being had improved. Chest radiograph showed minimal left-side pleural thickening but no pleural effusion. Subsequent follow-up visits were unremarkable and she was discharged from the chest clinic.

\section{Discussion}

To establish the diagnosis of chylothorax requires determining the presence of chylomicrons, ${ }^{1}$ but in clinical practice, lipoprotein analysis of pleural fluid is seldom performed. Instead chylous pleural effusion is conventionally diagnosed when the pleural fluid contains a triglyceride level of more than $110 \mathrm{mg} / \mathrm{dL}(1.24 \mathrm{mmol} / \mathrm{L})$. Despite this widely accepted definition, in a retrospective analysis Maldonado et $\mathrm{al}^{2}$ found that only $44 \%$ of patients with chylothorax had the classical milky appearance, and 14\% had a triglyceride level of less than $110 \mathrm{mg} / \mathrm{dL}$.

Our patient's diagnosis of chylothorax was confirmed, but the etiology was never determined. Known causes of chylothorax can broadly be divided into surgical and nonsurgical causes. ${ }^{2,3}$ Surgical causes include coronary artery bypass, esophageal resection, pleural resection, and trauma. Non-surgical causes include neoplasms, tuberculosis, liver cirrhosis, and hypothyroidism. Idiopathic chylothorax made up $9 \%$ of chylothoraces in one study. ${ }^{2}$

We treated our patient conservatively, with intercostal tube drainage, medium-chain triglycerides oil, and total parenteral nutrition for more than 3 weeks. With failure of conservative therapy, surgery would have been appropriate ${ }^{3}$ but she refused. To facilitate chyle drainage from the pleural cavity we employed intrapleural streptokinase, which improved her condition. To our knowledge, there have been neither studies nor case reports of intrapleural streptokinase for treatment of chylothorax. Intrapleural 
streptokinase is conventionally used in cases of complicated parapneumonic effusion, empyema thoracis, and malignant pleural effusion. ${ }^{4-7}$

Our patient with chylothorax failed conservative therapy, but intrapleural streptokinase markedly improved her condition. The use of intrapleural streptokinase for chylothorax is not established, and further studies are required to determine its role as an alternative to surgery.

\section{REFERENCES}

1. Staats BA, Ellefson RD, Budahn LL, Dines DE, Prakash UB, Offord $\mathrm{K}$. The lipoprotein profile of chylous and nonchylous pleural effusions. Mayo Clin Proc 1980;55(11):700-704.
2. Maldonado F, Hawkins FJ, Daniels CE, Doerr CH, Decker PA, Ryu JH. Pleural fluid characteristics of chylothorax. Mayo Clin Proc 2009;84(2):129-133.

3. Talwar A, Lee HJ. A contemporary review of chylothorax. Indian J Chest Dis Allied Sci 2008;50(4):343-351.

4. Heffner JE. Multicenter trials of treatment of empyema: after all these years. N Engl J Med 2005;352(9):926-928.

5. Sahn SA. Use of fibrinolytic agents in the management of complicated parapneumonic effusions and empyema. Thorax 1998;53(Suppl 2):S65-S72.

6. Diacon AH, Theron J, Schuurmans MM, Van de Wal BW, Bollige CT. Intrapleural streptokinase for empyema and complicated parapneumonic effusions. Am J Respir Crit Care Med 2004;170(1):4953.

7. Maskell NA, Gleeson FV. Effect of intrapleural streptokinase on a loculated malignant pleural effusion. N Engl J Med 2003;348(14):e4. 